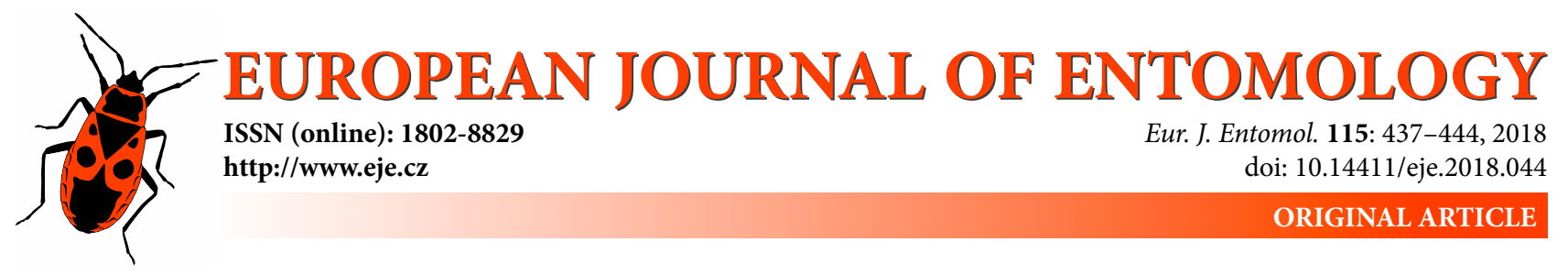

\title{
Dryophthorinae weevils (Coleoptera: Curculionidae) of the forest floor in Southeast Asia: Three-marker analysis reveals monophyly of Asian Stromboscerini and new identity of rediscovered Tasactes
}

\author{
VASILY V. GREBENNIKOV \\ Canadian Food Inspection Agency, 960 Carling Ave., Ottawa, ON, K1A 0Y9, Canada; \\ e-mail: vasily.grebennikov@inspection.gc.ca
}

Key words. Curculionidae, Dryophthorinae, Tasactes, COI, ITS2, 28S, phylogeny, clogging taxonomy, China, Nepal, Myanmar

\begin{abstract}
The nominal genus Tasactes Faust, 1894, consisting of two originally included nominal species from Myanmar, is rediscovered for the first time since being erected. Adult weevils herein assigned to the taxonomically re-defined Tasactes were abundant in forest floor litter at five localities in China (Yunnan and Sichuan), plus one specimen is available from Shaanxi and three from Nepal. Phylogenetic analysis of a 2,275 bp matrix concatenated from one mitochondrial (COI) and two nuclear markers (ITS2 and 28S) revealed that the monophyletic Tasactes consists of eight evolutionary significant terminal clades, either allopatric (three) or sympatric (two on Cang Shan in Yunnan and three on Mount Emei in Sichuan). The genus Tasactes is nested within the monophyletic Stromboscerini, while the tribe is sister to monophyletic Dryophthorus. The two morphological diagnostic characters of Tasactes, which are unique within the tribe, are the transversely truncated antennal club and conically projecting velvety apex of the club. So defined, Tasactes renders the genus Orthosinus paraphyletic. Considering the taxonomic neglect and uncertainties surrounding nominal Stromboscerini, all herein reported members of this tribe, including the Tasactes, are not assigned to Linnaean species. This paper illustrates the "clogging taxonomy" phenomenon, in which obscure historical names render taxonomic assignment of newly sampled specimens precarious. All the data used herein (localities, sequences, specimen images) are available online in public datasets dx.doi.org/10.5883/DS-TASACT1 and dx.doi.org/10.5883/DS-TASACT2.
\end{abstract}

\section{INTRODUCTION}

This paper was motivated by the discovery of numerous minute and slow-moving Stromboscerini weevils (Fig. 1A) recorded (Figs 1B-E) when forest leaf litter in Southwest China and nearby areas was sifted (Fig. 5 and Supplementary Table S1). The original plan of producing an integrated phylogeny using DNA, morphology and other data sources was abandoned once the grossly unsatisfactory state of Stromboscerini taxonomy became apparent (Grebennikov, 2018). The nominal tribe lacks an underlying phylogenetic hypothesis and is likely to be multiply non-monophyletic (Grebennikov, 2018). The type genus from Madagascar was thought to be unrelated to the rest of the tribe distributed mainly in Southeast Asia (Grebennikov, 2018), potentially leaving all but the type genus without a tribal assignment. Furthermore, doubts remain about the monophyly of all non-monotypic Recent Stromboscerini genera. The widely accepted and century old synonymy of the type species of the genus Xerodermus is doubted (Grebennikov, 2018), which threatens the taxonomic identity of the genus. It became evident that any research on the numerous newly sampled Stromboscerini would be haunted by the phenomenon of "clogging taxonomy" (Grebennikov, 2016), in which poorly understood historical names render the usage of the Linnaean nomenclature very unreliable.

The nominal genus Tasactes was chosen as the focus of this paper because its phylogenetic identity as a clade detected using a DNA-based phylogenetic analysis could be clearly linked with a nominal genus through a pivotal combination of diagnostic morphological characters. The history of human encounter with these weevils, herein referred to as the genus Tasactes, is exceedingly short. Johannes Faust (1894) established the genus for two new species, $T$. carinulatus Faust, 1894 (Fig. 10A in Grebennikov, 2018) and T. interruptus Faust, 1894 (Fig. 10B in Grebennikov, 2018). Both type series were collected by Leonardo Fea in March 1887 on "Mt. Mooleyit" (likely Mount Mulayit Taung at $16^{\circ} 11^{\prime} \mathrm{N}$ and $98^{\circ} 31^{\prime} \mathrm{E}$ of the Dawna Range) in southern Myanmar (Fig. 5). Although all three names were later mentioned in various catalogues (i.e. Alonso-Zarazaga \& Lyal, 1999), the type species of Tasactes remains undesignated and no specimens of the genus, other than the type series, are reported.

This paper has two main goals, both aimed at carrying out the first phylogenetic analysis of the tribe Stromboscerini. The first goal is to test the implied monophyly of the 

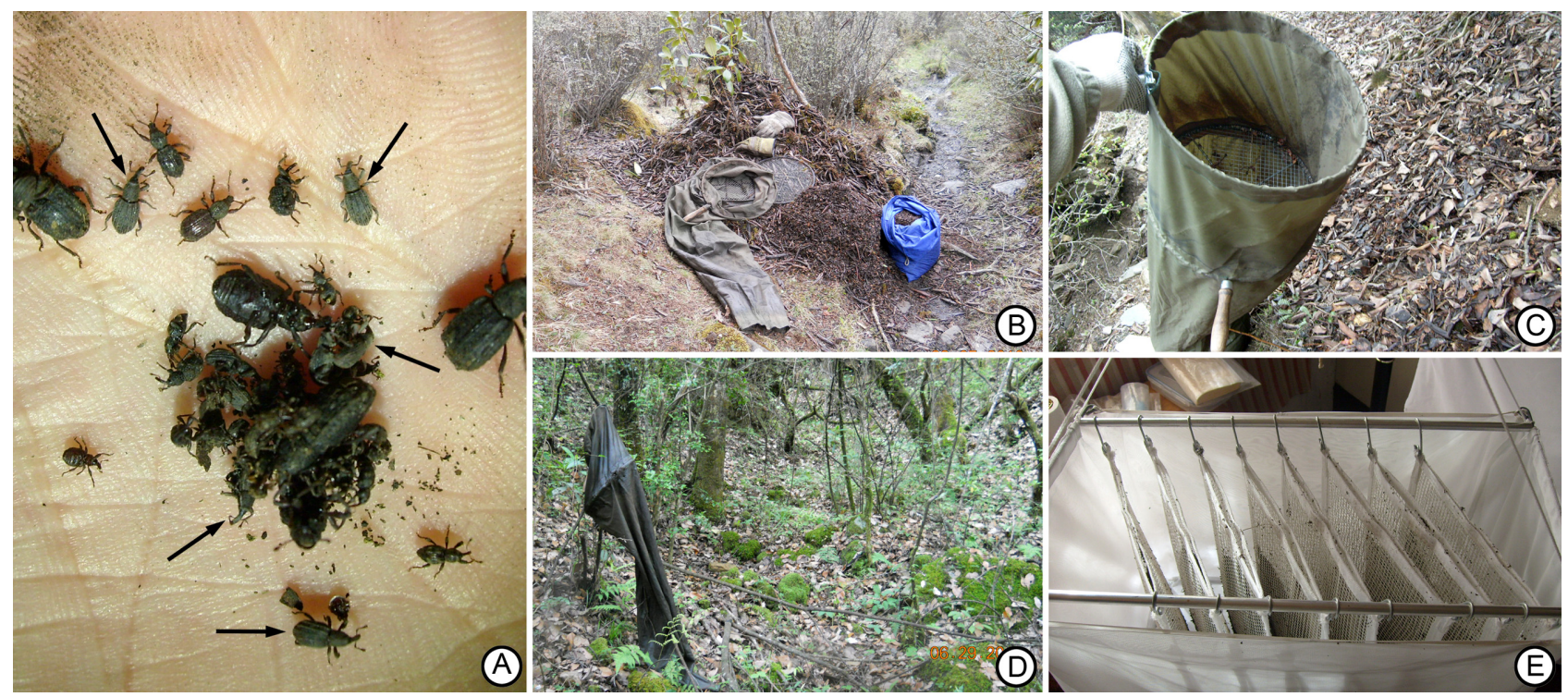

Fig. 1. Stromboscerini weevils. A - weevils extracted from a sample of typical forest floor litter collected on Mount Emei, Sichuan, China; arrows indicate Stromboscerini; B - sample of litter in a bag prior to sifting through a $12 \times 12 \mathrm{~mm}$ mesh and then through a $7 \times 7 \mathrm{~mm}$ mesh; C - sifter with $12 \times 12 \mathrm{~mm}$ mesh; D - forest floor litter habitat of Stromboscerini weevils; E - Winkler funnel with litter suspended in mesh bags.

tribe, and if monophyletic, then to hypothesise its sistergroup and shed light on its internal phylogenetic structure. The second goal is to anchor one of the inadequately known historical genus-group names (Tasactes) to a newly detected clade. Overall, this paper was designed as another example (Riedel, 2017) of the work required on taxonomically and phylogenetically orphaned groups, when newly hypothesized clades may for the first time be linked with old and inadequately known nominal taxa.

\section{MATERIAL AND METHODS}

\section{Specimen sampling and handling}

A total of 145 sifted samples of forest litter were collected in mainland China (122), Vietnam (7) and Taiwan (16); their twoletter two-digit codes are explained in Supplementary Table S1. Litter was sifted using a hand-held sifter (Figs 1B-D) first through $12 \times 12 \mathrm{~mm}$ mesh, then through an insert (Fig. 1B) with a finer $7 \times 7 \mathrm{~mm}$ mesh. Live specimens (Fig. 1A) were extracted using suspended Winkler funnels (Fig. 1E) and preserved in $96 \%$ ethanol. A few specimens were opportunistically collected by means other than litter sifting (mainly by hand), while specimens from Nepal (clade E in Fig. 3) were received from Joachim Schmidt; these specimens do not have litter sample codes (Table 2 ) and are denoted in Fig. 3 by country names. All the specimens have a label with the code CNCCOLVG0000XXXX serving as a Sample ID in the Barcode of Life Database (= BOLD, Ratnasingham \& Hebert, 2007, www.bold.org), while the last four digits serve as unique specimenidentifiers (Figs 2-4 and Table 2). All the specimens studied were adults and are deposited in the Canadian National Collection of Insects, Arachnids and Nematodes in Ottawa, Canada (CNC).

\section{Specimen selection for DNA barcoding and Neighbour Joining ( $\mathrm{NJ}$ ) clustering}

Sixty specimens of Dryophthorinae (36 of Tasactes and 15 of four other Stromboscerini genera) were DNA barcoded (= sequencing of 658 bp of COI-5', Hebert et al., 2003a, b). All laboratory work (including DNA extraction, purification, PCR and bidirectional sequencing) was performed in a commercial laboratory "Canadian Center for DNA Barcode" (CCDB, http://www. ccdb.ca/) at the University of Guelph, Ontario, Canada, following the standard laboratory protocol (Ivanova et al., 2006, 2014). A cocktail of two primer pairs was used to amplify the DNA barcoding fragment (Supplementary Table S2). Obtained sequences, electropherograms, gel images, specimen data and specimen images (Supplementary Fig. S1) can be seen online in the public BOLD dataset available at dx.doi.org/10.5883/DS-TASACT1. Alignment of these sequences was easy as they contained no insertions/deletions (= indels), while their NJ clustering was performed using the online BOLD engine.

\section{Three-marker matrix formation and Maximum Likelihood $(\mathrm{ML})$ analysis}

A subset containing 45 Dryophthorinae terminals was selected and sequenced for two additional nuclear DNA markers, ITS2 and 28S (Table 1), using the primers in Supplementary Table S2. A total of 21 Tasactes and 15 other Stromboscerini terminals were selected (Table 2) to best represent clusters recovered in the NJ analysis (Supplementary Fig. S2). To place Stromboscerini in a wider phylogenetic context and test its taxonomically-implied monophyly, nine non-Stromboscerini terminals were incorporated in the analysis, including two terminals representing the likely closely related genus Dryophthorus Germar, 1824 (Gunter et al., 2016, Fig. 2 and Table 2). In the absence of a phylogenetic hypothesis for Stromboscerini and Dryophthorinae (and to avoid an excessive number of indels in noncoding and fast evolving ITS2 when a distant organism is added to the matrix), no non-Dryophthorinae terminals were added to root the topology. All reported and newly generated DNA sequences, as well as their electropherograms, gel images, specimen data and specimen images can

Table 1. DNA fragments used in analyses.

\begin{tabular}{lccccc}
\hline Gene & $\#$ & $\min$ & $\max$ & aligned & positions \\
\hline CO1-5' & 45 & 576 & 658 & 658 & 1 to 658 \\
ITS2 & 45 & 334 & 678 & 998 & 659 to 1656 \\
28S & 43 & 329 & 580 & 619 & 1657 to 2275 \\
\hline
\end{tabular}




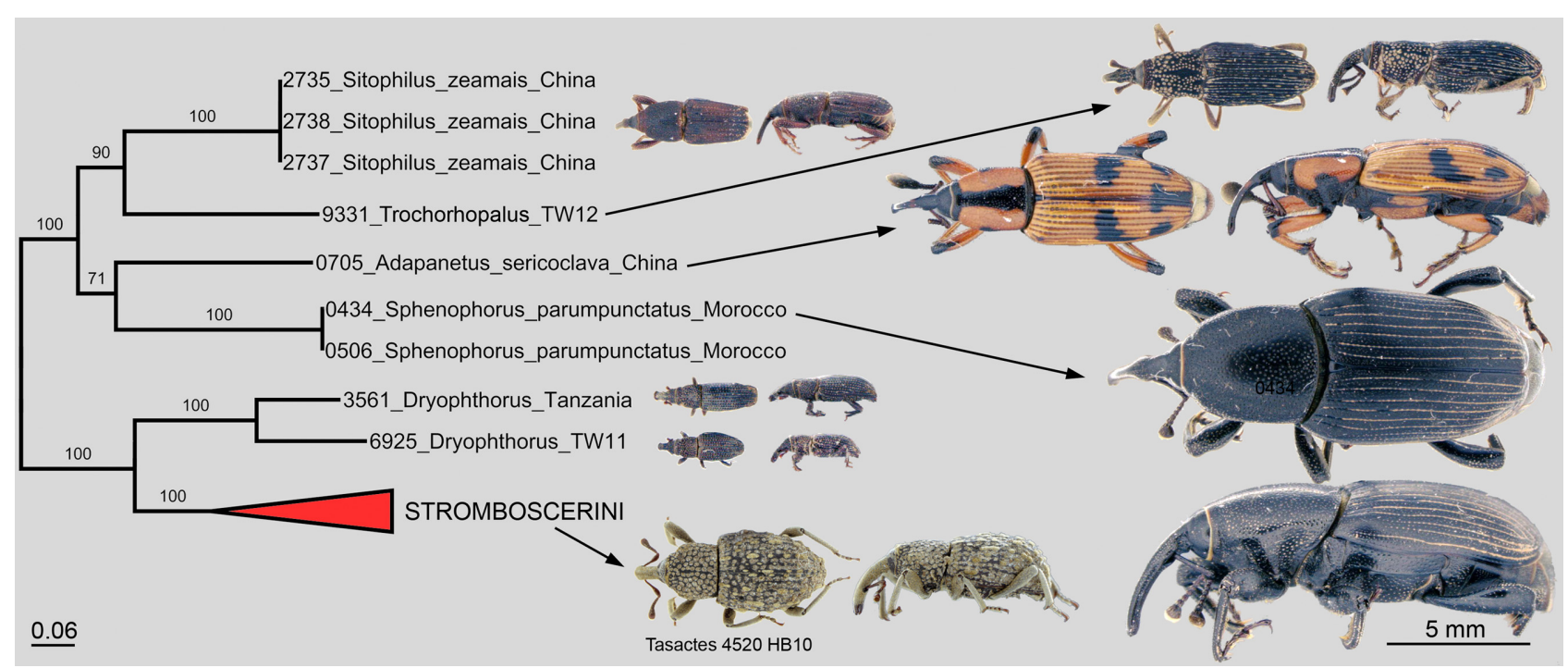

Fig. 2. Unrooted Maximum Likelihood inference phylogram of Dryophthorinae weevils based on the analysis of the concatenated $2,275 \mathrm{bp}$ matrix. Digits at internodes are bootstrap values. Images are to scale and illustrate corresponding tree terminals.

Table 2. GenBank accession numbers of Dryophthorinae weevils; for sample code see Table S1.

\begin{tabular}{|c|c|c|c|c|c|c|c|}
\hline Specimen & Species & Country & Locality & Sample & $\mathrm{CO} 1$ & ITS2 & $28 S$ \\
\hline 0434 & Sphenophorus parumpunctatus & Morocco & Tiznit & $\mathrm{n} / \mathrm{a}$ & HM417724 & KY110320 & KY110384 \\
\hline 0506 & Sphenophorus parumpunctatus & Morocco & Tiznit & $\mathrm{n} / \mathrm{a}$ & HM417726 & MG968848 & MG968904 \\
\hline 0705 & Adapanetus sericoclava & China & Emei Shan & $\mathrm{n} / \mathrm{a}$ & HQ987004 & MG968817 & MG968874 \\
\hline 0766 & Tasactes & China & Cang Shan & $\mathrm{CNO} 2$ & HQ987041 & MG968836 & MG968893 \\
\hline 0790 & Tasactes & China & Cang Shan & $\mathrm{CNO} 04$ & HQ987059 & MG968821 & MG968878 \\
\hline 0876 & Tasactes & China & Cang Shan & CN16 & HQ987108 & MG968834 & MG968891 \\
\hline 1058 & Orthosinus & China & Gaoligong Shan & GL15 & HQ986782 & MG968833 & MG968890 \\
\hline 1060 & Orthosinus & China & Gaoligong Shan & GL15 & HQ986783 & MG968822 & MG968879 \\
\hline 1061 & Orthosinus & China & Gaoligong Shan & GL15 & HQ986784 & MG968813 & none \\
\hline 1092 & Tasactes & China & Emei Shan & EM13 & HQ986795 & MG968839 & MG968896 \\
\hline 1133 & Tasactes & China & Emei Shan & EM15 & HQ986820 & MG968853 & MG968909 \\
\hline 1166 & Tasactes & China & Emei Shan & EM17 & HQ986846 & MG968827 & MG968884 \\
\hline 1171 & Tasactes & China & Emei Shan & EM17 & HQ986851 & MG968824 & MG968881 \\
\hline 1215 & Tasactes & China & Emei Shan & EM18 & HQ986875 & MG968854 & MG968910 \\
\hline 2283 & Tetrasynommatus & China & Emei Shan & EM24 & MG968932 & MG968838 & MG968895 \\
\hline 2325 & Tetrasynommatus & China & Emei Shan & EM25 & MG968938 & MG968844 & MG968900 \\
\hline 2373 & Tasactes & China & Emei Shan & EM27 & MG968919 & MG968820 & MG968877 \\
\hline 2405 & Tasactes & China & Gongga Shan & GN03 & MG968925 & MG968828 & MG968885 \\
\hline 2519 & Tasactes & China & Gongga Shan & GN10 & MG968916 & MG968818 & MG968875 \\
\hline 2554 & Tasactes & China & Gongga Shan & GN15 & MG968927 & MG968830 & MG968887 \\
\hline 2690 & Tasactes & China & Cang Shan & CN19 & MG968943 & MG968847 & MG968903 \\
\hline 2705 & Tasactes & China & Cang Shan & CN20 & MG968946 & MG968850 & MG968906 \\
\hline 2735 & Sitophilus zeamais & China & Gongga Shan & $\mathrm{n} / \mathrm{a}$ & KJ672255 & MG968837 & MG968894 \\
\hline 2737 & Sitophilus zeamais & China & Gongga Shan & $n / a$ & MG968933 & MG968840 & MG968897 \\
\hline 2738 & Sitophilus zeamais & China & Gongga Shan & $\mathrm{n} / \mathrm{a}$ & MG968936 & MG968842 & MG968899 \\
\hline 3561 & Dryophthorus & China & Gongga Shan & $\mathrm{n} / \mathrm{a}$ & MG968913 & MG968814 & MG968871 \\
\hline 4120 & Orthosinus & China & Cang Shan & CN06 & MG968917 & MG968819 & MG968876 \\
\hline 4177 & Tasactes & China & Emei Shan & EM13 & MG968923 & MG968825 & MG968882 \\
\hline 4187 & Tasactes & China & Emei Shan & EM13 & MG968911 & MG968811 & MG968869 \\
\hline 4310 & Orthosinus & Vietnam & Tam Dao & TD02 & MG968924 & MG968826 & MG968883 \\
\hline 4330 & Allaeotes & Vietnam & Tam Dao & TD02 & MG968948 & MG968852 & MG968908 \\
\hline 4331 & Allaeotes & Vietnam & Tam Dao & TD02 & MG968930 & MG968835 & MG968892 \\
\hline 4334 & Orthosinus & Vietnam & Tam Dao & TD02 & MG968929 & MG968832 & MG968889 \\
\hline 4346 & Orthosinus & Vietnam & Tam Dao & TD03 & MG968940 & MG968846 & MG968902 \\
\hline 4401 & Allaeotes & Vietnam & Tam Dao & TD06 & MG968939 & MG968845 & MG968901 \\
\hline 4520 & Tasactes & China & Haba Shan & HB10 & MG968928 & MG968831 & MG968888 \\
\hline 4570 & Tasactes & China & Haba Shan & HB17 & MG968937 & MG968843 & none \\
\hline 6925 & Dryophthorus & Taiwan & Lija Road & TW11 & MG968914 & MG968815 & MG968872 \\
\hline 6967 & Dexipeus & Taiwan & Lija Road & TW14 & MG968915 & MG968816 & MG968873 \\
\hline 6974 & Dexipeus & Taiwan & Lija Road & TW15 & MG968935 & MG968841 & MG968898 \\
\hline 6980 & Dexipeus & Taiwan & Lija Road & TW16 & MG968926 & MG968829 & MG968886 \\
\hline 7781 & Tasactes & Nepal & Barun Valley & $\mathrm{n} / \mathrm{a}$ & MG968947 & MG968851 & MG968907 \\
\hline 7782 & Tasactes & Nepal & Barun Valley & $n / a$ & MG968921 & MG968823 & MG968880 \\
\hline 7783 & Tasactes & Nepal & Barun Valley & $\mathrm{n} / \mathrm{a}$ & MG968945 & MG968849 & MG968905 \\
\hline 9331 & Trochorhopalus & Taiwan & Lija Road & TW12 & MG968912 & MG968812 & MG968870 \\
\hline
\end{tabular}




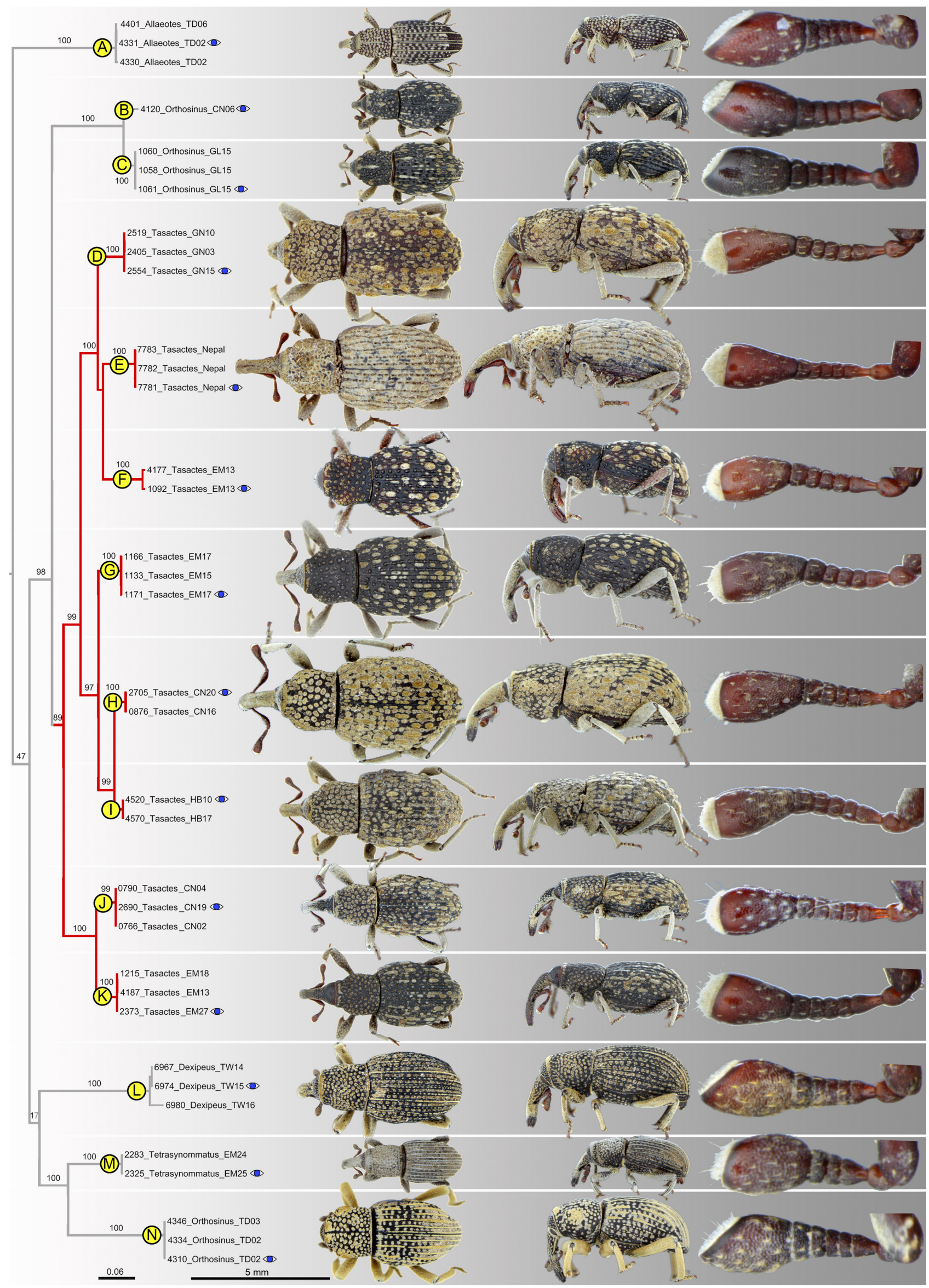

Fig. 3. Rooted Maximum Likelihood inference phylogram of monophyletic Asian Stromboscerini based on the analysis of the concatenated $2,275 \mathrm{bp}$ matrix. Digits at internodes are bootstrap values. Fourteen evolutionary significant terminal clades are labelled A-N; eight of them belonging to the monophyletic genus Tasactes are in red. Blue eye signs indicate illustrated terminals; habitus images are to scale. 

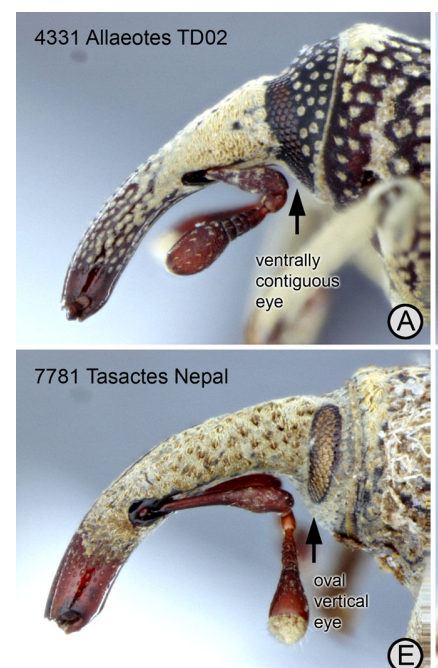

(E)
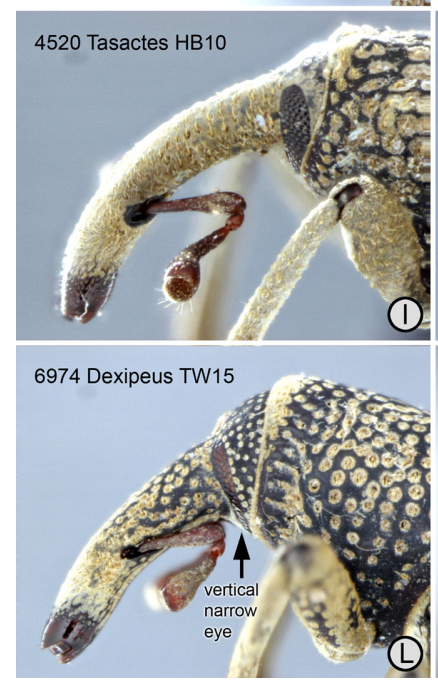
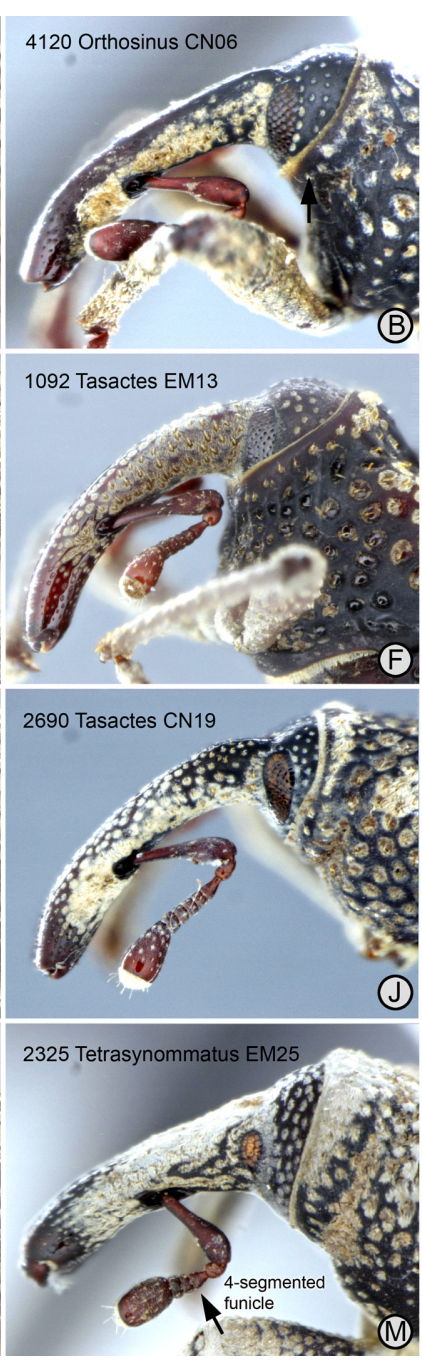
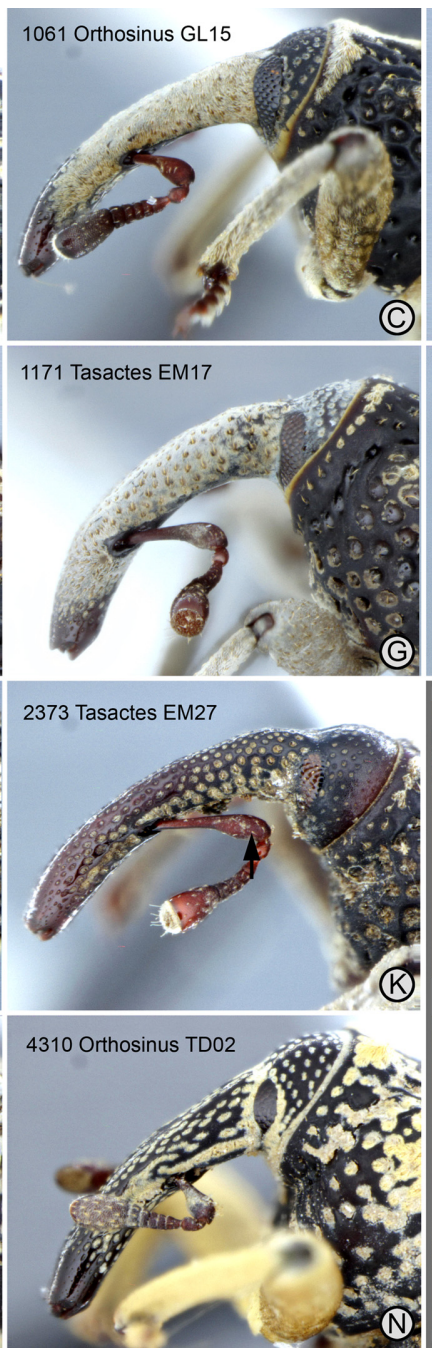
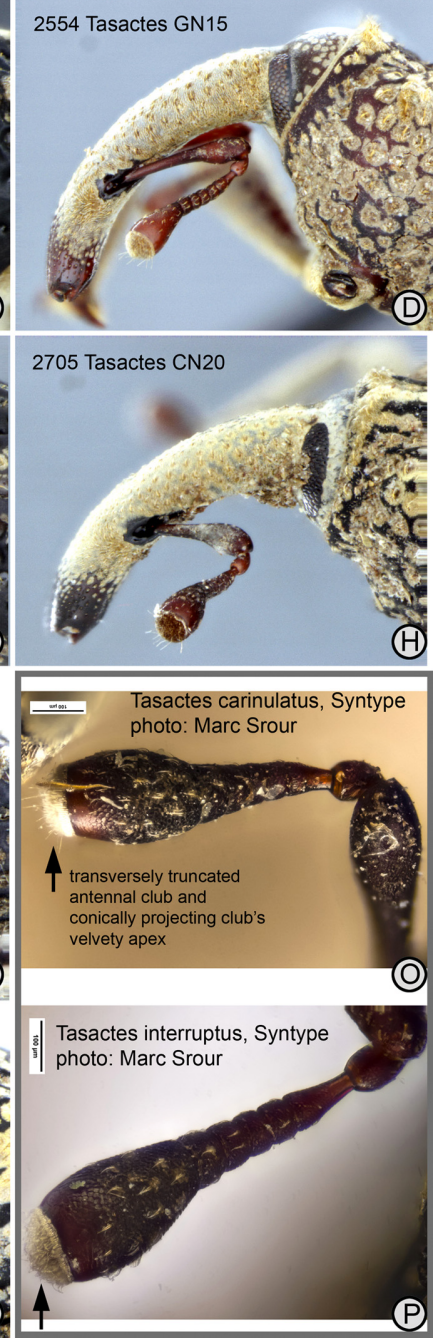

Fig. 4. Stromboscerini weevils. A-N - heads, left lateral view illustrating fourteen evolutionary significant terminal clades as in Fig. 3; O-P - antennae of syntypes of both nominal Tasactes species.

be seen online in the public BOLD dataset DS-TASACT2 available at dx.doi.org/10.5883/DS-TASACT2.

Alignment of the ITS2 and 28S sequences was done using the MAFFT 7 online platform (Katoh et al., 2002, Katoh \& Toh, 2008a) with the Q-INS-i algorithm (Katoh \& Toh, 2008b) utilising the information on the secondary structure. No parts of the three alignments were excluded from the analysis. Three aligned single-fragment datasets were concatenated using Mesquite 3.11 (Maddison \& Maddison, 2011). Analysis of the 2,275 bp concatenated dataset was done using the ML phylogenetic method and the RAxML 7.2.7 (Stamatakis et al., 2008) algorithm on a computer cluster at the Cyberinfrastructure for Phylogenetic Research (CIPRES) (Miller et al., 2010) with 100 non-parametric bootstrap (Felsenstein, 1985) replicates. The topologies were visualized using FigTree v1.4 (Rambaut, 2014).

\section{Matching names and clades, specimen visualization and the limitations of this study}

To link the Stromboscerini clades with five nominal genera, primary types of all Recent valid genera of the tribe were studied (Grebennikov, 2018), including the syntypes of both nominal Tasactes species stored in the "Senckenberg Naturhistorische Sammlungen Dresden" in Dresden, Germany. Morphological characters given in the key to Stromboscerini genera (Morimoto, 1985) were also used. To visualize the adult morphology of Stromboscerini and link it with the DNA topology, habitus and antennae of specimens of all 14 evolutionary significant terminal clades (= ESTC, = candidate species) were imaged and superimposed on the phylogenetic tree (Figs 2, 3). Since sexual dimorphism has never been reported or noted in the Stromboscerini, no attempt was made to sex specimens. Lacking comparative data on the genitalia, no attempt was made to use this source of information. No new taxonomic acts (such as the description of new taxa or designation of the type species of Tasactes) are herein performed, since such actions would require an effort far exceeding the scope of this paper, which aims to provide the very first phylogenetic glimpse of the old and poorly known nominal taxa associated with the vaguely defined family-group name "Stromboscerini".

\section{RESULTS}

The ML tree of 45 terminals analyzed using the concatenated 2,275 bp matrix recovered the monophyletic Stromboscerini as a sister to the monophyletic Dryophthorus; all three clades have $100 \%$ bootstrap support (Fig. 2). All 36 Stromboscerini terminals are grouped in 14 ESTC (clades A-N in Fig. 3), each with high bootstrap support (99-100\%); eight of these clades (D-K in Fig. 3, in red) form the monophyletic Tasactes with bootstrap support of $89 \%$. Relationships among eight Tasactes clades are well-resolved with high bootstrap support (97-100\%), 


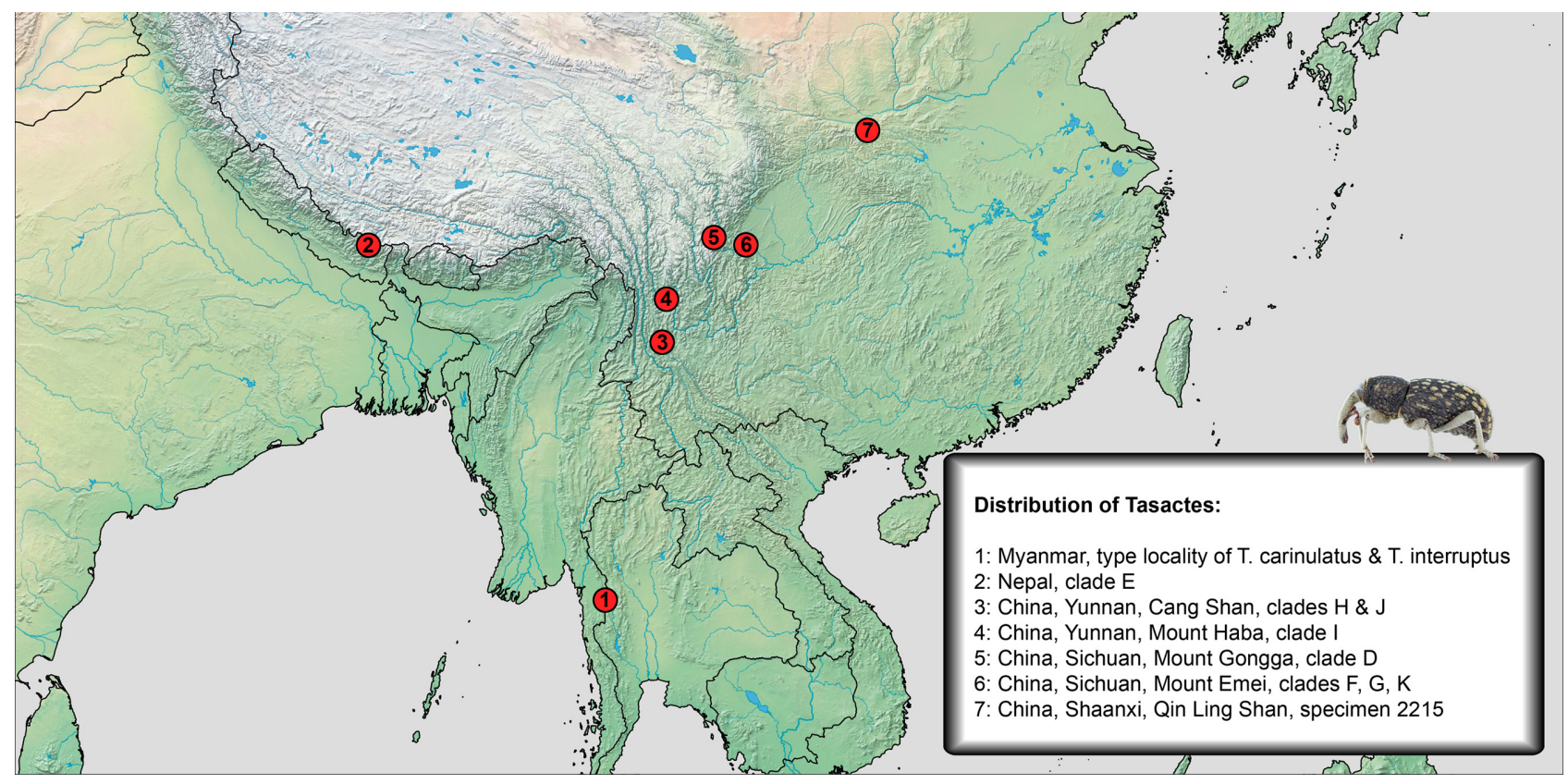

Fig. 5. Distribution of Tasactes. Map was prepared using online software SimpleMappr (Shorthouse, 2010); the northeastern record is based on a single specimen that was not included in the concatenated analysis (Fig. 3), but DNA barcoded and clusters with other Tasactes as a sister to clade G (Fig. S2).

and clade $\mathrm{J}+\mathrm{K}$ is a sister to the rest of the genus (clades $\mathrm{D}-\mathrm{I})$, which itself is made up of two clades: $\mathrm{D}+(\mathrm{E}+\mathrm{F})$ and $\mathrm{G}+(\mathrm{H}+\mathrm{I})$. Orthosinus Motschulsky, 1863, the only genus besides Tasactes represented in the analysis by more than one ESTC, is non-monophyletic, with one of its two clades (clade $\mathrm{B}+\mathrm{C}$ ) being a sister to Tasactes, while clade $\mathrm{N}$ is a sister to Tetrasynommatus Morimoto, 1985 (Fig. 3).

\section{DISCUSSION}

\section{Monophyly and sister group of Stromboscerini}

Recovery of the strongly supported clade formed by reciprocally monophyletic Dryophthorus and Stromboscerini is one of the two most significant results of this study. Even though this relationship was recently, and for the first time hypothesized (Gunter et al., 2016) in a study also using three DNA markers (28S, $16 \mathrm{~S}$ and COI), the reported clade's statistical support was notably lower (83-85\%). Even more significantly, in Gunter et al. (2016) the tribe Stromboscerini is represented by a single terminal of Dryophthoroides Roelofs, 1879, thus leaving this tribe's monophyly untested. The herein reported analysis utilizing representatives of five nominal Stromboscerini genera is the first adequately designed and successful attempt to test tribe monophyly. Both "aberrant" genera of Stromboscerini (Nephius Pascoe, 1885 and Stromboscerus Schoenherr, 1838) are uniquely characterized by having ocular lobes on the anterior edge of the prothorax (Morimoto, 1985: 74) and thought to be unrelated to the rest of the tribe (Grebennikov, 2018), were not included in the present analysis, thus postponing the decisive test of the tribe's monophyly (and of its name, since the latter is the type genus).

\section{Monophyly of Tasactes}

The second most significant result is that all morphological diagnostic characters of nominal Tasactes (Morimoto 1985: 74: elongate and ventrally non-contiguous eyes, 6-segmented antennal funicle, transversely truncated antennal club and conically projecting velvet apex to the club) occur in the specimens forming clade D-K (Fig. 3). Most significantly, all specimens in this clade clearly display both club characters (Figs 4O, P), which among all Stromboscerini are unique to this genus. Remarkably, both club characters are not mentioned by Johannes Faust in the original generic description, but were first reported nearly a century later by Morimoto $(1978,1985)$. It might also be noted that four antennomers immediately proximal to the club in all specimens herein attributed to Tasactes are nearly subquadrate, while in all other herein examined Stromboscerini they are about 1.5 times as wide as long (Fig. 3 ). This unique morphological match, as well as the relative similarity in habitus (Fig. 10 in Grebennikov, 2018) and geographical distribution (Fig. 5) of the type specimens of both nominal Tasactes species and those forming clade D-K (Fig. 2), are the decisive factors supporting the linkage between the genus-group name and the herein so named clade. It should be added that within the herein re-defined genus Tasactes, clade D-I might be separated from clade $\mathrm{J}-\mathrm{K}$ by two diagnostic characters of the former: larger body size (Fig. 3) and evenly bent rostrum (Fig. 4).

\section{Flight ability of Stromboscerini}

An inability to fly is a widespread phenomenon in Pterygota and weevils (Arzanov \& Grebennikov, 2017). Even though the flight ability of Stromboscerini was not studied and the herein analyzed specimens were not systematically 
examined for the presence of full-sized hind wings, members of Allaeotes Pascoe, 1885 differ from the rest of the tribe by having non-effaced elytral shoulders (= humeri present, Fig. 3) and being trapped by flight intercept traps (specimens from Vietnam provided by Adam Brunke, not included in the present analysis), both of which indicate that members of this genus can fly. The sister-group relationship between the supposedly volant genus Allaeotes (clade A in Fig. 3) and the supposedly flightless rest of the tribe (clade B-N in Fig. 3) indicates that flight capacity in Stromboscerini was irreversibly lost by the most recent common ancestor of clade B-N.

\section{Elusive identity of Orthosinus and Xerodermus}

The recovered Stromboscerini topology (Fig. 2) indicate that the genus Orthosinus currently containing seven nominal species from Sri Lanka, India, Myanmar, China, Indonesia and Japan (Grebennikov, 2018) is not monophyletic. Not only is it represented by two clades (clade B-C and clade $\mathrm{N}$ in Fig. 3) that are distinctly different in eye shape (Figs 4B, C, N), but there are numerous additional specimens attributable to this genus according to the key to genera (Morimoto, 1985), which were not included in the present analysis. The mystery is compounded by the existence of the nominal genus Xerodermus Lacordaire, 1866, with four nominal species in Sri Lanka and India (Grebennikov, 2018). This nominal genus was a synonym of $\mathrm{Or}$ thosinus when the most recent key to the tribe's genera was published (Morimoto, 1985), but was then resurrected as a valid genus (Alonso-Zarazaga \& Lyal, 2002), even though the taxonomic identity of its type species is doubtful (Grebennikov, 2018). Both genera seem to represent the tribe's "garbage bin", accommodating all species not assignable to other easier-to-recognize nominal genera characterized, likely, by apomorphic character states (such as 4- or 5-segmented antennal funicle or by exceedingly narrow vertical eyes). Identifying and determining the phylogenetic limits of these two relatively large nominal genera is, therefore the main challenge to matching the taxonomy and phylogeny of the tribe.

ACKNOWLEDGEMENTS. J. Schmidt (Admannshagen, Germany) collected and made available specimens of Tasactes from Nepal (clade E in Fig. 3). A. Brunke (Ottawa, Canada) provided specimens of Allaeotes from FIT samples collected by him in Vietnam. M. Alonso-Zarazaga (Madrid, Spain) identified the specimens of Adapanetus Guenther, 1936 and Trochorhopalus Kirsch, 1877 used in this analysis (Fig. 2). K.-D. Klass and O. Jäger (both Dresden, Germany) facilitated visits to Senckenberg Naturhistorische Sammlungen Dresden to study the type series of both nominal species of Tasactes. M. Srour (Dresden, Germany) took images of the antennal clubs of Tasactes (Figs 4O, P). A. Slater (Ottawa, Canada) critically read an earlier version of the manuscript prior to its submission, while L. Chamorro (Washington, D.C., USA) reviewed the MS.

\section{REFERENCES}

Alonso-Zarazaga M.A. \& Lyal C.H.C. 1999: A World Catalogue of Families and Genera of Curculionoidea (Insecta Coleoptera) (excepting Scolytidae and Platypodidae). Entomopraxis, Barcelona, $315 \mathrm{pp}$.
Alonso-Zarazaga M.A. \& Lyal C.H.C. 2002: Addenda and corrigenda to ' $A$ World Catalogue of Families and Genera of Curculionoidea (Insecta: Coleoptera)'. —Zootaxa 63: 1-37.

ArZanov Y.G. \& GrebenniKov V.V. 2017: Cleonini (Coleoptera: Curculionidae: Lixinae) are monophyletic and flightless: tribe overview, rampant adult homoplasy and illustrated global diversity. - Zootaxa 4329: 1-63.

FAust J. 1894: Viaggio di Leonardo Fea in Birmania e regioni vicine. LX. Curculionidae. - Ann. Mus. Genova Stor. Nat. Genova 34: 153-370.

Felsenstein J. 1985: Phylogenies and the comparative method. Am. Nat. 125: 1-15.

Grebennikov V.V. 2016: Flightless Catapionus (Coleoptera: Curculionidae: Entiminae) in Southwest China survive the Holocene trapped on mountaintops: new species, unknown phylogeny and clogging taxonomy. - Zootaxa 4205: 243-254.

GrebenNikov V.V. 2018: Dryophthorinae weevils (Coleoptera: Curculionidae) of the forest floor in Southeast Asia: illustrated overview of nominal Stromboscerini genera. - Zootaxa 4418 : 121-135.

Gunter N.L., Oberprieler R.G. \& Cameron S.L. 2016: Molecular phylogenetics of Australian weevils (Coleoptera: Curculionoidea): exploring relationships in a hyperdiverse lineage through comparison of independent analyses. - Austral Entomol. 55: 217-233.

Hebert P.D.N., Cywinska A., Ball S.L. \& DeWaArd J.R. 2003a: Biological identifications through DNA barcodes. - Proc. $R$. Soc. Lond. (B) 270: 313-321.

Hebert P.D.N., Ratnasingham S. \& DeWaard J.R. 2003b: Barcoding animal life: cytochrome c oxidase subunit 1 divergences among closely related species. - Proc. R. Soc. Lond. (B) 270: 96-99.

Ivanova N.V., DeWaArd J.R. \& Hebert P.D.N. 2006: An inexpensive, automation-friendly protocol for recovering high-quality DNA. - Mol. Ecol. Notes 6: 998-1002.

Ivanova N.V., DeWaard J.R., Hajibabaei M. \& Hebert P.D.N. 2014: Protocols for High-volume DNA Barcode Analysis. URL: https://www.researchgate.net/profile/Paul_Hebert2/ publication/238509959_Protocols_for_High-Volume_DNA Barcode_Analysis/links/53d169190cf220632f393902/ Protocols-for-High-Volume-DNA-Barcode-Analysis. pdf? origin=publication_detail

КАтон K. \& Тон H. 2008a: Recent developments in the MAFFT multiple sequence alignment program. - Briefings Bioinform. 9: $286-298$.

КАтоH K. \& Тон H. 2008b: Improved accuracy of multiple ncRNA alignment by incorporating structural information into a MAFFT-based framework. - BMC Bioinform. 9: 212, 13 pp.

Katoh K., Misawa K., Kuma K. \& Miyata T. 2002: MAFFT: a novel method for rapid multiple sequence alignment based on fast Fourier transform. - Nucl. Acids Res. 30: 3059-3066.

Maddison W.P. \& Maddison D.R. 2001: Mesquite: A Modular System for Evolutionary Analysis. Ver. 3.04. URL: https:// www.mesquiteproject.org/

Miller M.A., Pfeiffer W. \& Schwartz T. 2010: Creating the CIPRES Science Gateway for inference of large phylogenetic trees. In Proceedings of the Gateway Computing Environments Workshop (GCE), 14 Nov. 2010, New Orleans, LA. pp. 1-8.

Mовімото K. 1978: Check-list of the family Rhynchophoridae (Coleoptera) of Japan, with descriptions of a new genus and five new species. - Esakia 12: 103-118.

Morimoto K. 1985: Supplement to the check-list of the family Rhynchophoridae (Coleoptera) of Japan, with descriptions of a new genus and four new species. - Esakia 23: 67-76. 
Rambaut A. 2014: FigTree, Ver. 1.4. URL: http://tree.bio.ed.ac. uk/software/figtree/ (last accessed 12 Mar. 2014).

Ratnasingham S. \& Hebert P.D.N. 2007: BOLD: the barcode of life data system. - Mol. Ecol. Notes 7: 355-364.

Riedel A. 2017: The weevil genera Nyphaeba Pascoe and Pantiala Pascoe and the problems of an unstable nomenclature in orphaned taxa. - Zootaxa 4244: 377-389.

Shorthouse D.P. 2010: SimpleMappr, an Online Tool to Produce Publication-Quality Point Maps. URL: http://www.simplemappr.net (last accessed 12 Mar. 2014).
Stamatakis A., Hoover P. \& Rougemont J. 2008: A rapid bootstrap algorithm for the RAxML web servers. - Syst. Biol. 57: 758-771.

Received March 12, 2018; revised and accepted July 19, 2018 Published online August 24, 2018

Supplementary file: http://www.eje.cz/2018/044/S01.pdf.

Table S1. List of the localities sampled.

Table S2. List of the primers used.

Fig. S1. Images of 60 DNA barcoded Dryophthorinae.

Fig. S2. Neighbour joining clustering of 60 DNA barcoded Dryophthorinae performed using the online BOLD tree-building engine and Kimura 2 parameter. 